Acta Crystallographica Section B

Structural

Science

ISSN 0108-7681

Editor: Carolyn P. Brock

The incommensurately modulated structure of a tricyclic natural-product-like compound of empirical formula $\mathrm{C}_{22} \mathrm{H}_{20} \mathrm{O}_{3}$

Nicolas Guiblin, Cyril A. Fuhrer, Robert Häner, Helen Stoeckli-Evans, Kurt Schenk and Gervais Chapuis

Copyright $($ International Union of Crystallography

Author(s) of this paper may load this reprint on their own web site provided that this cover page is retained. Republication of this article or its storage in electronic databases or the like is not permitted without prior permission in writing from the IUCr. 
Acta Crystallographica Section B

Structural

Science

ISSN 0108-7681
Nicolas Guiblin, ${ }^{\text {a* }}$ Cyril A. Fuhrer, ${ }^{b}$ Robert Häner, ${ }^{b}$ Helen Stoeckli-Evans, ${ }^{c}$ Kurt Schenk $^{\mathrm{a}}$ and Gervais Chapuis ${ }^{a}$

\footnotetext{
aLaboratoire de Cristallographie, École Polytechnique Fédérale de Lausanne, Institut de Physique de la Matière Complexe, $\mathrm{CH}-1015$ Lausanne, Switzerland, ${ }^{\mathbf{b}}$ Departement für Chemie und Biochemie, Universität Bern, Freiestrasse 3, CH-3012 Bern, Switzerland, and ${ }^{\mathbf{c}}$ Institut de Microtechnique, Université de Neuchâtel, Rue Emile Argand 11, Case Postale 158, CH-2009 Neuchâtel, Switzerland
}

\section{The incommensurately modulated structure of a tricyclic natural-product-like compound of empirical formula $\mathrm{C}_{22} \mathrm{H}_{20} \mathrm{O}_{3}$}

3,4-Diphenyl-2a, 5a, 6, 7,8,8a,8b-heptahydro-furo[4,3,2-de]chromen-2-one (1) was prepared as part of a project aimed at the synthesis of polycyclic natural-product-like scaffolds. $\mathrm{X}$-ray analysis of crystals grown from ethanol revealed an incommensurately modulated structure. Data include main and satellite reflections up to second order. The modulation vector was refined using the $N A D A$ program. The modulated character of the structure of the organic compound $\mathrm{C}_{22} \mathrm{H}_{20} \mathrm{O}_{3}$ is interpreted in terms of the intermolecular $\mathrm{C}-\mathrm{H} \cdots \mathrm{O}$ hydrogen bonds and close-contact approximation.

\section{Introduction}

Incommensurate modulated structures are part of a larger group of aperiodic crystals also including composite and quasicrystalline materials. The diffraction pattern of crystals with an incommensurate modulation is characterized by a series of reflections, which require additional integers to define them. In order to model the complete set of observations, it is convenient to represent the structure in a space of dimension larger than three. The dimension of the space is given by the number of integer indices required to completely characterize the diffraction pattern and is called the superspace. The current method is essentially based on the work of de Wolff (1974, 1977) and Janner \& Janssen (1979).

As part of the efforts aimed at the synthesis of naturalproduct-like compounds (Messer et al., 2004, 2005), we became interested in compound (1). This tricyclic compound was synthesized in analogy with the previously published procedure (Fuhrer et al., 2004). Upon recrystallization of (1) from ethanol, preliminary structural investigations by X-ray diffraction showed that this compound exhibits an incommensurate character at $173 \mathrm{~K}$.

Although incommensurate structures appear frequently in inorganic (Baldinozzi et al., 1998; Boucher et al., 1996; Miles et al., 1998; Shaw et al., 1988; Speziali \& Pimenta, 2004) or metalorganic materials (Lam et al., 1995; Meyer et al., 1994; Steurer \& Depmeier, 1989), fewer reports are available to date concerning organic compounds (Zuñiga et al., 1989; Schönleber \& Chapuis, 2004).

The present study is part of a project based on the understanding of the origin of the aperiodic character in organic materials by diffraction methods (Bussien Gaillard et al., 1996, 1998) and also from molecular dynamical simulations (Pan et al., 2002, 2003). The validity of the method presented here is evident just by comparing the magnitude of the anisotropic displacement parameters obtained from the superspace refinement and the conventional refinement. In addition, via the quality of the refinement it is possible to obtain very
Received 20 October 2005 Accepted 13 March 2006 
Table 1

Experimental details.

\begin{tabular}{|c|c|}
\hline \multicolumn{2}{|l|}{ Crystal data } \\
\hline Chemical formula & $\mathrm{C}_{22} \mathrm{H}_{20} \mathrm{O}_{3}$ \\
\hline$M_{r}$ & 332.4 \\
\hline Cell setting, space group & Monoclinic, $P 2_{1} / c$ \\
\hline Temperature $(\mathrm{K})$ & 173 \\
\hline$a, b, c(\AA)$ & 7.2527 (9), 24.951 (3), 9.8959 (10) \\
\hline$\beta\left({ }^{\circ}\right)$ & $106.645(8)$ \\
\hline$V\left(\AA^{3}\right)$ & $1715.8(4)$ \\
\hline$Z$ & 4 \\
\hline$D_{x}\left(\mathrm{Mg} \mathrm{m}^{-3}\right)$ & 1.286 \\
\hline Radiation type & Mo $K \alpha$ \\
\hline $\begin{array}{l}\text { No. of reflections for cell para- } \\
\text { meters }\end{array}$ & 6774 \\
\hline$\theta$ range $\left(^{\circ}\right)$ & $1.6-25.6$ \\
\hline$\mu\left(\mathrm{mm}^{-1}\right)$ & 0.09 \\
\hline Crystal form, colour & Rod, colourless \\
\hline Crystal size (mm) & $0.50 \times 0.22 \times 0.20$ \\
\hline \multicolumn{2}{|l|}{ Data collection } \\
\hline Diffractometer & Stoe IPDS-II \\
\hline Data collection method & $\omega$ scans \\
\hline Absorption correction & None \\
\hline $\begin{array}{l}\text { No. of measured, independent and } \\
\text { observed reflections }\end{array}$ & 12976,40 786, 12976 \\
\hline Criterion for observed reflections & $I>3 \sigma(I)$ \\
\hline$R_{\text {int }}$ & 0.0375 \\
\hline$\theta_{\max }\left({ }^{\circ}\right)$ & 51.6 \\
\hline \multirow[t]{3}{*}{ Range of $h, k, l$} & $-8 \Rightarrow h \Rightarrow 8$ \\
\hline & $-29 \Rightarrow k \Rightarrow 29$ \\
\hline & $-11 \Rightarrow l \Rightarrow 11$ \\
\hline Intensity decay (\%) & 2 \\
\hline \multicolumn{2}{|l|}{ Refinement } \\
\hline Refinement on & $F^{2}$ \\
\hline$R\left[F^{2}>2 \sigma\left(F^{2}\right)\right], w R\left(F^{2}\right), S$ & $0.039,0.087,0.79$ \\
\hline No. of reflections & 40786 \\
\hline No. of parameters & 328 \\
\hline $\mathrm{H}$-atom treatment & Constrained to parent site \\
\hline Weighting scheme & $\begin{array}{l}\text { Based on measured s.u.'s } \\
\qquad w=1 /\left[\sigma^{2}(I)+0.0004 I^{2}\right]\end{array}$ \\
\hline$(\Delta / \sigma)_{\max }$ & 0.001 \\
\hline$\Delta \rho_{\max }, \Delta \rho_{\min }\left(\mathrm{e} \AA^{-3}\right)$ & $0.13,-0.14$ \\
\hline Extinction method & $\begin{array}{l}\text { B-C type } 1 \text { Gaussian isotropic } \\
\text { (Becker \& Coppens, 1974) }\end{array}$ \\
\hline Extinction coefficient & $0.78(3)$ \\
\hline
\end{tabular}

Computer programs used: JANA2000 (Petříček et al., 2003).

precise indications of the atomic interactions leading to the incommensurability.

\section{Experimental}

\subsection{Sample preparation and data collection}

Compound (1) was prepared according to the previously published method (Fuhrer et al., 2004). Full experimental details have been deposited. ${ }^{1}$ Suitable crystals were obtained after recrystallization from an ethanol solution. A colourless rod-like crystal of dimensions $0.50 \times 0.22 \times 0.22 \mathrm{~mm}^{3}$ was used for data collection. The intensity data were collected at $173 \mathrm{~K}$ on a Stoe IPDS II diffractometer equipped with a two-

\footnotetext{
${ }^{1}$ Supplementary data for this paper are available from IUCr electronic archives (Reference: OG5016). Services for accessing these data are described at the back of the journal.
}

circle goniometer and using Mo $K \alpha$ graphite monochromated radiation. Experimental details are given in Table 1.

\subsection{Initial structure solution}

The observed systematic absences for main reflections are compatible with the monoclinic space group $P 2_{1} / c$ (No. 14).

An initial structure solution was performed using direct methods by means of the program SHELXS (Sheldrick, 1990). The refinement and all further calculations were carried out using SHELXL97 (Sheldrick, 1999). The H atoms were included in calculated positions and treated as riding atoms using SHELXL default parameters.

$\mathrm{C}-\mathrm{H}$ distances were fixed at $0.97 \AA$. 45 atoms were then used to describe the structure. In order to help with the description of the structure, we propose to distinguish it by considering three different parts (Fig. 1): the two phenyl rings and the rest of the molecule, later referred to as RB3 (C1 to $\mathrm{C} 10, \mathrm{O} 1, \mathrm{O} 2$ and O3), RB1 (the phenyl ring described by atoms $\mathrm{C} 17$ to $\mathrm{C} 22$ and linked to the RB3 unit by $\mathrm{C} 1$ ) and $\mathrm{RB} 2$ (the phenyl ring described by atoms $\mathrm{C} 11$ to $\mathrm{C} 16$ and linked to the RB3 unit by $\mathrm{C} 2$ ), the term RB meaning rigid body and this approximation being used later in the refinement. $\mathrm{H}$ atoms, not indicated here, are named according to their parent $\mathrm{C}$ atom.

The non-H atoms were refined using anisotropic atomic displacement parameters (ADP). Hydrogen ADPs were considered isotropic (IDP) and fixed to their respective linked $\mathrm{C}$ atoms by the following equation: $U_{\text {iso }}(\mathrm{H})=1.2 U_{\text {eq }}(\mathrm{C})$, with $U_{\text {eq }}=(1 / 3) \sum_{i=1}^{3} \sum_{j=1}^{3} U^{i j} a_{i}^{*} a_{j}^{*} a_{i} \cdot a_{j}$.

The average structure, corresponding to the Fourier transform of the main reflections in real space (Schaniel et al., 2002), is represented in Fig. 2. The corresponding $R$ value, obtained from 4977 reflections with $I>3 \sigma(I)$ and 226 refined parameters, is 0.0546. The ORTEP (Farrugia, 1997) representation of the structure shows large ADP ellipsoids. The ADP values are large mainly along the $b$ direction for all of the atoms, i.e. along the long axis of the molecule.

The packing of the structure is represented in Fig. 3. The molecules are stacked perpendicularly to the $c$ axis, two nearest neighbours being related by the $c$ glide. Such a row of

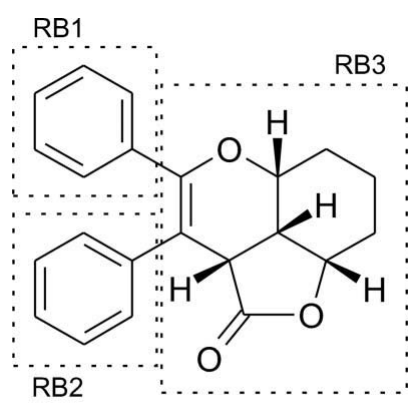

Figure 1

$(+/-)-1$

The 3,4-diphenyl-2a,5a,6,7,8,8a,8b-heptahydro-furo[4,3,2-de]chromen-2one molecule. The different parts used in the text to describe the molecule are represented. The $(+/-)$ symbol indicates the racemic composition of this molecule. 
molecules is repeated along the $a$ axis, thus forming a layer of layer group $P c$. These layers are then stacked on top of each other perpendicularly to the $b$ axis, realising the maximum degree of order.

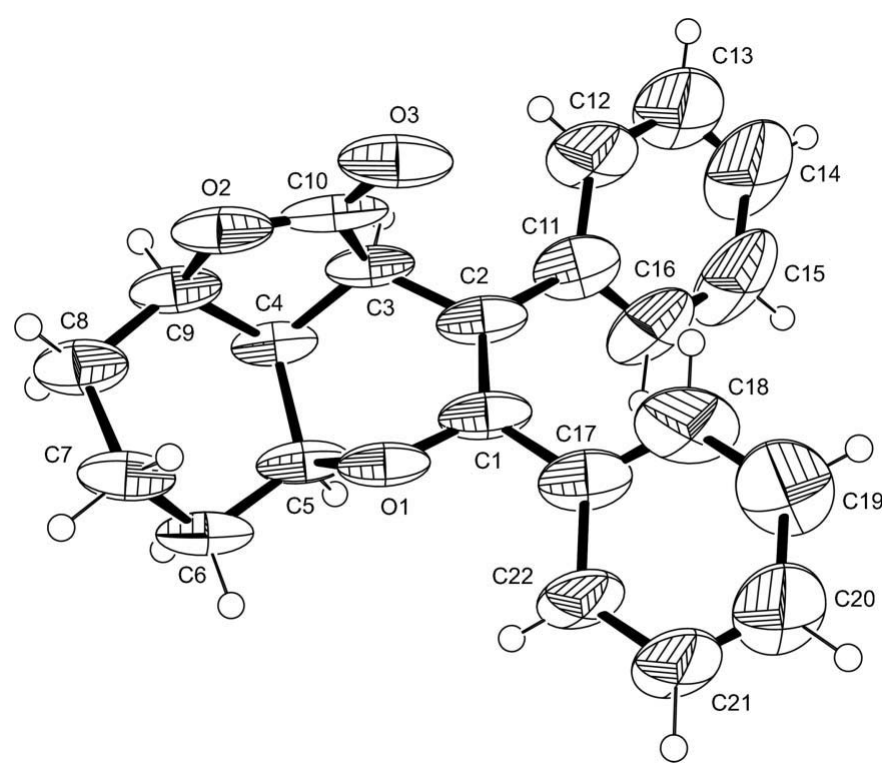

Figure 2

The molecular structure, obtained from the refinement of main reflections, showing $50 \%$ probability displacement ellipsoids and the crystallographic numbering scheme. For clarity, $\mathrm{H}$ atoms are drawn as open circles of arbitrary diameter.

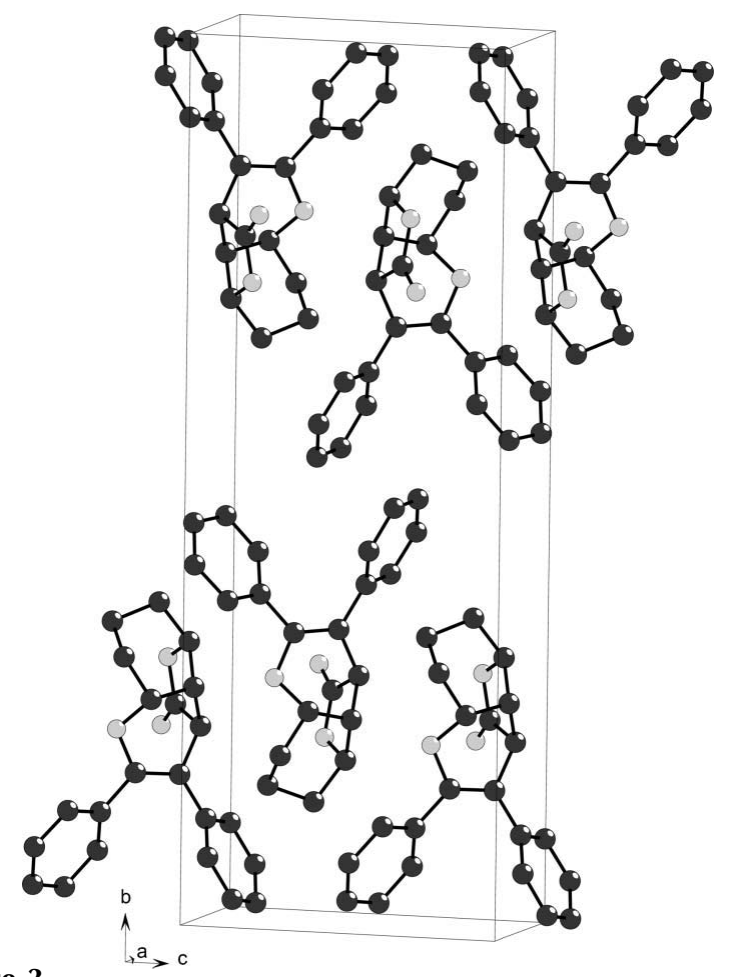

Figure 3

$\rightarrow a c$

Drawing of the unit cell of the packing arrangement corresponding to the average structure. This packing shows the $c$-glide relation existing between molecules stacked perpendicularly to the $c$ axis. $\mathrm{H}$ atoms have been omitted for clarity.

\subsection{The incommensurately modulated structure}

The modulated character of this structure is associated with the existence of satellite reflections as indicated in Fig. 4. The diffraction pattern can be fully indexed by introducing the modulation vector $\mathbf{q}$ defined by the relation $\mathbf{H}=h \mathbf{a}^{*}+k \mathbf{b}^{*}+$ $l \mathbf{c}^{*}+m \mathbf{q}$. The symbol $m$ represents the order of the satellite reflections. The modulation is called commensurate if the modulation vector components are rational, and incommensurate if at least one component is irrational.

Satellite reflections can be considered as a projection of a four-dimensional lattice in four-dimensional space $R_{4}$ onto three-dimensional space $R_{3}$.

A modulation can be displacive, i.e. displacement of atomic coordinates, occupational, i.e. a probabilistic occupation of a crystallographic site, or induced by thermal motion where the modulation occurs in the ADPs. For a displacive modulation the position $\mathbf{r}$ of an atom is described by the coordinates $x_{i}(i=$ $1,2,3,4)$ in $R_{4}$ with $x_{i}(i=1 \ldots 3)$ being the same coordinate as in $R_{3}$, and $x_{4}$ the position along the supplementary dimension. This position $\mathbf{r}$ is given by the relation $\mathbf{r}=\mathbf{r}_{0}+\mathbf{u}$. In the average structure the position of the atom is $\mathbf{r}_{0}$, and $\mathbf{u}$ defines the perturbation generating the satellite reflections. The perturbation is a periodic function of $\mathbf{q} \cdot \mathbf{r}$, the $u_{i}$ components of which can be decomposed into Fourier series, for the $i$ th atom in the unit cell, as

$$
u_{i}=\sum_{p=1}^{n} A_{i, p} \sin 2 \pi p\left(\mathbf{q} \cdot \mathbf{r}_{0}\right)+\sum_{p=1}^{n} B_{i, p} \cos 2 \pi p\left(\mathbf{q} \cdot \mathbf{r}_{0}\right) .
$$

The amplitude of the displacements is given by $A_{i, p}$ and $B_{i, p}$ for the $p$ th harmonic of the modulation function. The $x_{4}$ coordinate in superspace is defined as $t+\mathbf{q} \cdot \mathbf{r}$, where $t$ is a continuous function between 0 and 1 . Each section of the superspace with a specific value of $t$ represents a portion of three-dimensional space.

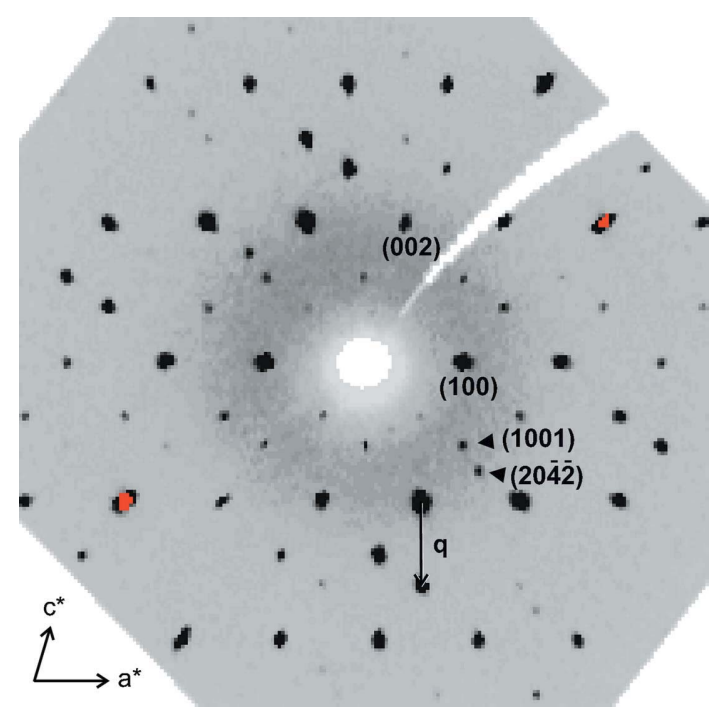

Figure 4

The $(h 0 l)$ plane showing the main, first- and second-order satellite reflections. The modulation vector $\mathbf{q}$ is indicated. 
The modulated structure was obtained by taking into account the complete set of observations extracted from the $X$-AREA integration software (Stoe, 2005). A reconstructed $h 0 l$ plane is represented in Fig. 4. Main and satellite reflections up to second order are clearly visible, with some of the satellites showing strong intensities.

The description of the modulated character of this structure requires a precise value for the components of the modulation vector. The program NADA (Schönleber et al., 2001) was used for this purpose. This program re-indexes the main and satellite reflections using the orientation matrix and the spatial peak positions. The refined modulation vector is obtained with standard uncertainties calculated analytically.

The refined modulation vector was $\mathbf{q}=0.2530(6) \mathbf{a}^{*}-$ $0.2123(7) \mathbf{c}^{*}$. The corresponding superspace group is $P 2_{1} / c(\alpha 0 \gamma)$. Using this modulation vector, satellite reflections are attached to main reflections that are systematically absent. As no satellite reflections are attached to main reflections, a reconsideration of the modulation vector had to be carried out. The modulation vector was transformed into an equivalent one, consistent with the previously indicated superspace group with the new modulation vector $\mathbf{q}=$ $0.2530(6) \mathbf{a}^{*}-1.2123(7) \mathbf{c}^{*}$.

The average structure was introduced as the starting model in the JANA2000 software (Petříček et al., 2003). The incommensurately modulated structure was refined by considering positional parameters with harmonic functions up to third order. The modulation functions were applied to the three rigid-body units, thus considerably reducing the number of refined parameters.
The $R$ ( $R$-weighted) values are 0.0331 (0.0657), 0.0434 (0.0766) and $0.0697(0.1581)$ for main, first- and second-order satellite observed reflections, respectively.

The $\mathrm{C}-\mathrm{H}$ distances and $\mathrm{H}$-atom positions were constrained as for the average structure. Nevertheless, a refinement without constraints was also performed. This should give better accuracy in $\mathrm{C}-\mathrm{H}$ distances (Schomaker \& Trueblood, 1968). However, the equation applied for calculating hydrogen IDPs was kept. The $R$ ( $R$-weighted) values are $0.0332(0.0648), 0.0435(0.0761)$ and $0.0703(0.1597)$ for main, first- and second-order satellite reflections, respectively. The $\mathrm{C}-\mathrm{H}$ distances vary in all the molecules from 0.967 (6) to 0.977 (7) $\AA$. As the deviations in $\mathrm{C}-\mathrm{H}$ distances are very limited, and if we consider the error in the distances, equal to the distance chosen for the constrained $\mathrm{C}-\mathrm{H}$ bond, then the applied constraints on the $\mathrm{H}$-atom positions are justified. This was done in order to reduce the number of refined parameters. The total number of refined parameters in the constrained model is then 328 , to be compared with 418 in the non-constrained model.

In the constrained refinement, the atomic positions vary mainly with the modulation along the $b$ axis. This variation is represented in Fig. 5, showing the displacement of atoms $\mathrm{C}$, $\mathrm{C} 17, \mathrm{C} 20, \mathrm{O} 3, \mathrm{C} 4$ and $\mathrm{C} 11$ as a function of the variable $t$.

By considering the amplitude of the variations of the displacement for atoms $\mathrm{C} 1, \mathrm{C} 17$ and $\mathrm{C} 20$, we notice an analogous variation for all displacements along $\mathbf{y}$, and an increase in amplitude for the $x$ and $z$ components from atoms $\mathrm{C} 1$ to $\mathrm{C} 17$ and to $\mathrm{C} 20$. We can deduce that the molecule moves as a whole along the $b$ axis, and that the phenyl rings possess
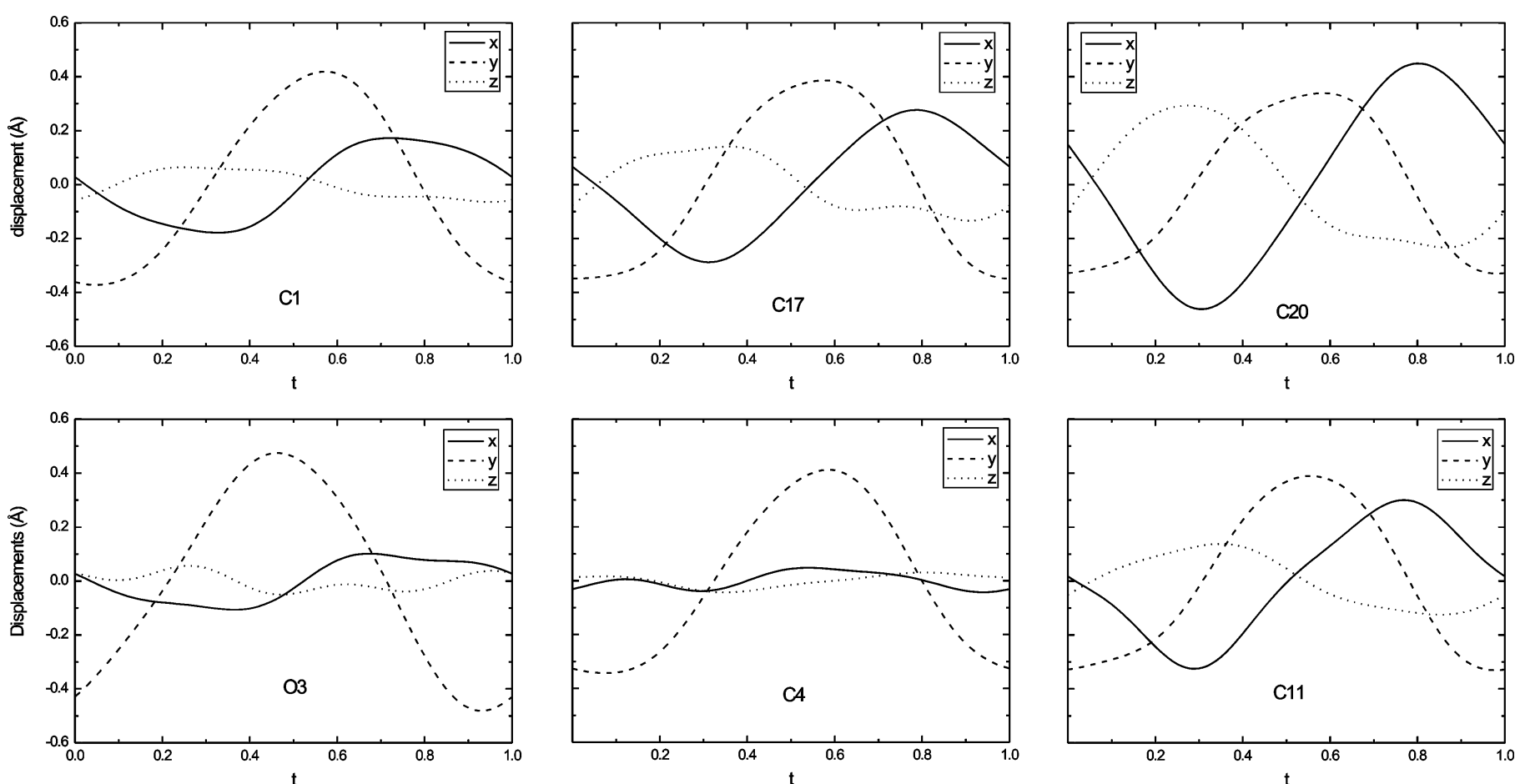

Figure 5

Modulation function of selected atoms along the $a, b$ and $c$ axis (represented by $x, y$ and $z$ coordinates, respectively), describing the displacement as a function of the incommensurate parameter $t$. The similar variation along the $b$ axis is clearly visible. The displacement for the phenyl rings (represented by atoms $\mathrm{C} 17$ and $\mathrm{C} 2$ ) is more important along the three axes than the rest of the molecule. All diagrams present the same $y$-axis scale. 


\section{research papers}

more degrees of freedom to move along the other directions. We observe that $\mathrm{C} 11$ and $\mathrm{C} 17$ present the same displacement along $t$, and that all of the $\mathrm{C}$ atoms from the RB1 and $\mathrm{RB} 2$ phenyl rings move with approximately the same amplitude. All the $\mathrm{O}$ atoms (only $\mathrm{O} 3$ is presented in Fig. 5) present the same behaviour with a slight displacement along the $x$ and $z$ axis.

The phenyl rings described as RB1 and RB2 units present small deviations compared with the basic hexagonal geometry. The $\mathrm{C}-\mathrm{C}-\mathrm{C}$ angles vary from 118.5 (4) to 120.9 (4) ${ }^{\circ}$ for $\mathrm{RB} 1$ and from 117.8 (4) to $121.2(4)^{\circ}$ for RB2, with a small variation along $t$. The atomic deviations from the planes of the two phenyl rings are very small, with a maximum distance from the basal plane of $\pm 0.009 \AA$ for $\mathrm{C}$ atoms.

The $\mathrm{C} 1=\mathrm{C} 2$ double bond presents a slight variation from planarity. This can be interpreted as a combination of twisting and antisymmetric out-of-plane torsion (Ermer \& Mason, 1982). The twist angles are $173.8(3)^{\circ}$ for $\mathrm{O} 1-\mathrm{C} 1-\mathrm{C} 2-\mathrm{C} 11$

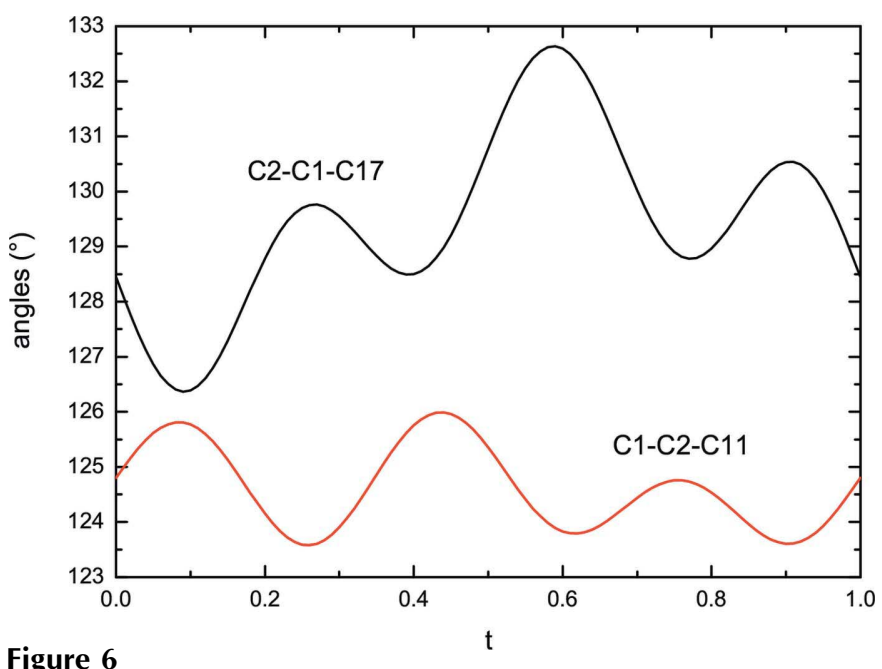

Figure 6

Variation of the angle of the two phenyl rings attached to the RB3 unit.

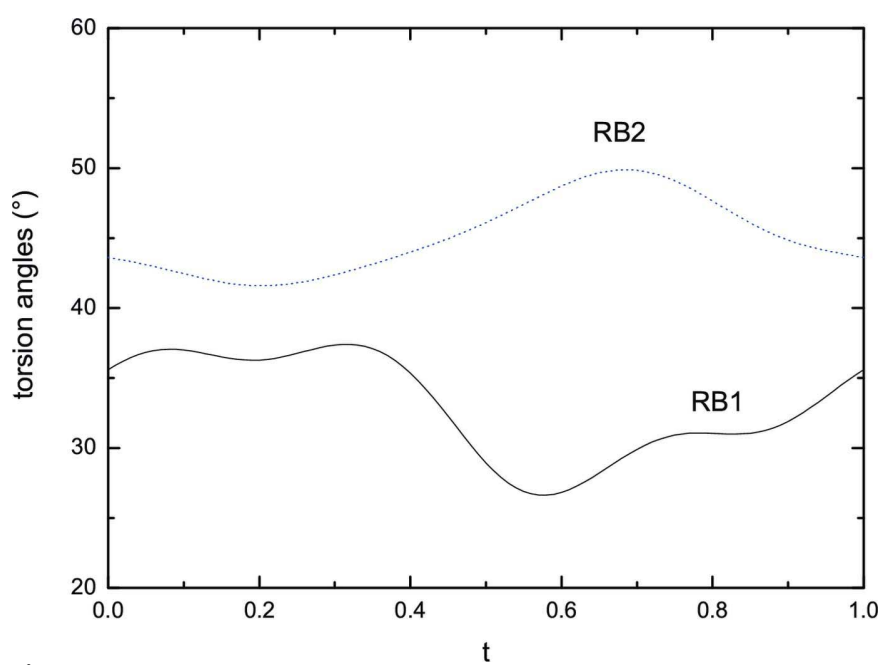

Figure 7

Variation of the torsion angles of the phenyl rings attached to the RB3 unit. Torsion angles are defined by $\mathrm{C} 2-\mathrm{C} 1-\mathrm{C} 17-\mathrm{C} 18$ for the RB1 unit and by $\mathrm{C} 1-\mathrm{C} 2-\mathrm{C} 11-\mathrm{C} 16$ for the $\mathrm{RB} 2$ unit. and $166.2(3)^{\circ}$ for $\mathrm{C} 3-\mathrm{C} 2-\mathrm{C} 1-\mathrm{C} 17$, which correspond to the average value considering the modulation parameter. Bending angles are $10.1(2)^{\circ}$ for $\mathrm{O} 1-\mathrm{C} 1-\mathrm{C} 2-\mathrm{C} 3$ and $9.9(3)^{\circ}$ for $\mathrm{C} 17-\mathrm{C} 1-\mathrm{C} 2-\mathrm{C} 11$. We must mention that the first torsion angle is constant whatever the modulation parameter $t$ considered, while the second torsion angle varies from 8.5 (3) to 10.9 (3) ${ }^{\circ}$ (Fig. 6).

The opposite behaviour of the two angles characterizing the position of the phenyl rings from the rest of the molecule indicates that they are displaced in phase, but with a larger variation for the RB1 unit.

If we consider the torsion angles of the two phenyl rings around the $\mathrm{C} 1-\mathrm{C} 17$ (respectively $\mathrm{C} 2-\mathrm{C} 11$ ) axis (Fig. 7) we observe that the two phenyl rings are also rotated in opposite directions. This can be understood if we consider the molecule viewed along its long axis. The clockwise rotation of the RB1 phenyl ring then induces an anticlockwise rotation for the RB2 phenyl ring.

Observation of the distances between the C17 and $\mathrm{C} 18$ atoms, and the $\mathrm{C} 11$ and $\mathrm{C} 16$ atoms from the RB1 and $\mathrm{RB} 2$ phenyl rings, respectively, shows that these distances are in fact less than the sum of the van der Waals radii, which corresponds to the close-contact approximation. The average values are 3.133 (7) $\AA$ (C17-C11), 3.262 (7) $\AA$ (C17-C16), 3.155 (7) $\AA$ (C18-C11) and 3.180 (7) $\AA$ (C16-C18). This explains the behaviour of the phenyl rings observed both in Figs. 6 and 7.

\section{Discussion}

As expected, the refinement of the modulated structure greatly reduces the ADP values for all the atoms obtained from the average structure. The corresponding ADPs are very

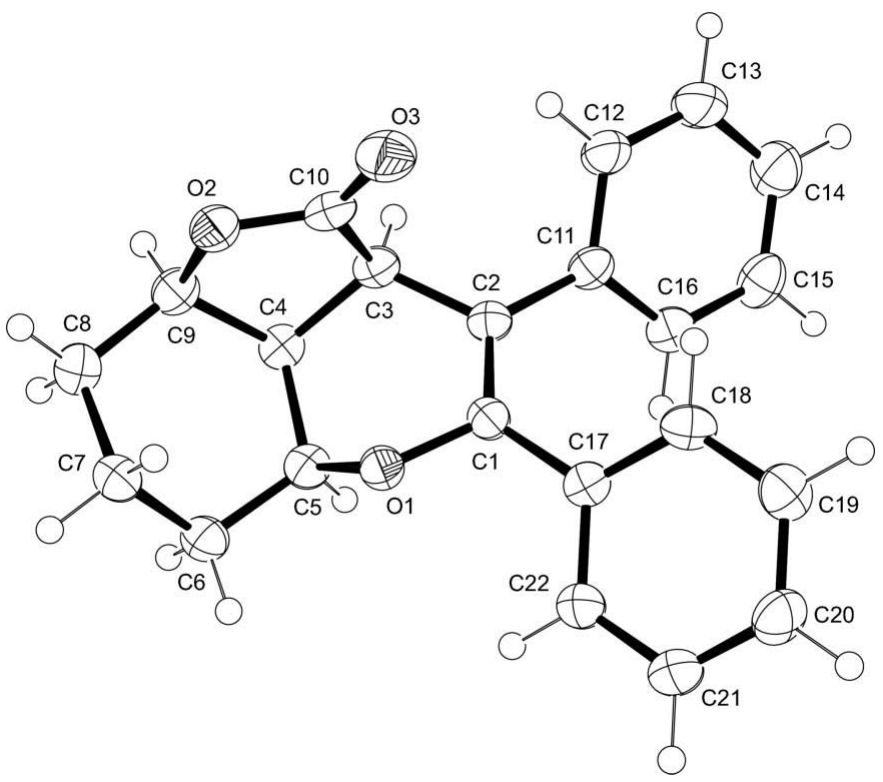

Figure 8

$O R T E P$ view of the structure showing the quasi-isotropic behaviour of all the atoms after the refinement of the modulation parameters. The ellipsoids are shown for the $50 \%$ probability level. 


\section{research papers}

regular for all atoms, leading to a quasi-isotropic behaviour of all the atoms. Fig. 8 shows an ORTEP representation of the molecule and must be compared with Fig. 2. The elongation of the ADP ellipsoids was corrected by the displacement of the structure along the $b$ axis induced by the modulation.

With the crystal packing shown in Fig. 3, some interactions between the molecules, in the form of hydrogen bonds, must be considered (Steiner, 1997). The layer stacking is exclusively mediated by van der Waals forces. In this structure the $\mathrm{C}-$ $\mathrm{H}$. . O interactions can occur in three ways, with the participation of the three different $\mathrm{O}$ atoms of the molecule. Considering that the hydrogen bond is preferentially aligned with a bonding angle between 150 and $180^{\circ}$ (Steiner \& Desiraju, 1998), only intermolecular hydrogen bonds occur in the crystal structure.

The strongest hydrogen bond of the structure is $\mathrm{C} 4-$ H4. . O 1 $\left(x, \frac{1}{2}-y, \frac{1}{2}+z\right)$. The distance varies with the modulation from 2.443 (5) to 2.510 (5) $\AA$. This hydrogen bond links the RB3 units within the layers of the molecule, as shown in Fig. 9. The $\theta$ angle $\mathrm{C}-\mathrm{H} \cdots \mathrm{O}$ describing the geometry of the hydrogen-bonding system varies from 167.30 (8) to $172.4(4)^{\circ}$ along the $t$ parameter.

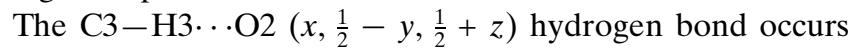
approximately in the same direction as the first described, with $\mathrm{O} \cdot \mathrm{H}$ distances varying from 2.707 (6) to 2.917 (6) $\AA$ and $\theta$ angles from $142.5(5)$ to $147.4(4)^{\circ}$.

The third hydrogen bond to be considered is $\mathrm{C} 22-$ $\mathrm{H} 22 \cdots \mathrm{O} 3(-1+x, y, z)$. In fact, three different hydrogen bonds should be considered which share the $\mathrm{O} 3$ atom, the other two being $\mathrm{C} 6-\mathrm{H} 62 \cdots \mathrm{O} 3$, with $\mathrm{H} \cdots \mathrm{O}$ distances varying from 2.870 (7) to 3.091 (6) $\AA$, and C5-H5 ‥O3, with $\mathrm{H} \cdots \mathrm{O}$ distances from 2.631 (4) to 2.914 (4) $\AA$. The reason why these two bonds are not retained is essentially due to the $\mathrm{C}-\mathrm{H} \cdots \mathrm{O}$ angle, $112.3(5)$ and $123.3(3)^{\circ}$ for the average values, respectively, which are in the lower limit of acceptance for a directional bond.

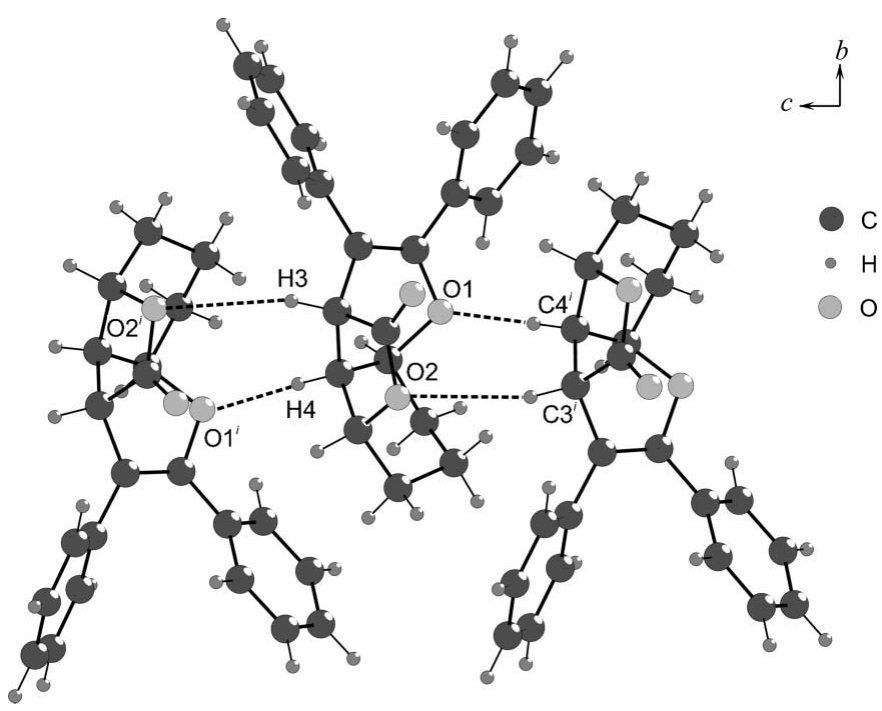

Figure 9

Packing of the structure showing the hydrogen bonds between atoms $\mathrm{O} 1$ and $\mathrm{H} 4$ and atoms $\mathrm{O} 2$ and $\mathrm{H} 3$ [symmetry code: (i) $x, \frac{1}{2}-y, \frac{1}{2}+z$ ].
The O3 $\cdots \mathrm{H} 22$ distances vary from $2.554(8)$ to 3.016 (10) $\AA$, and $\theta$ angles from 142.3 (7) to 153.7 (7) ${ }^{\circ}$. This hydrogen bond is established between the RB3 unit of a molecule and the RB1 phenyl ring of a neighbour molecule considering the $c$ axis. This interaction can be seen in Fig. 10.

The difference in the amplitude of the $\mathrm{C}-\mathrm{H} \cdots \mathrm{O}$ bond lengths with $t$ is essentially due to the displacement of the $\mathrm{C}$ atoms. The amplitude of $\mathrm{C} 3-\mathrm{H} 3 \cdots \mathrm{O} 2$ is three times larger than for $\mathrm{C} 4-\mathrm{H} 4 \cdots \mathrm{O} 1$, which can be compared with the amplitude of the displacement of the respective $\mathrm{C}$ atoms (see Fig. 5, C3 atom is displaced like C1). The same occurs for

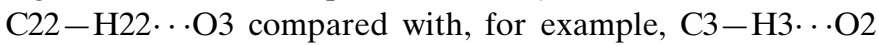
with twice the distance amplitude.

Owing to the existence of two hydrogen bonds between the RB3 unit in the crystal packing, this part of the molecule is stable with only a displacement along the $b$ axis with the $t$ parameter. The stability of this molecular part is also observed with the constant value of the $\mathrm{O} 1-\mathrm{C} 1-\mathrm{C} 2-\mathrm{C} 3$ torsion angle.

If we consider the two phenyl rings, one is linked to the RB3 unit of a neighbour molecule by a hydrogen bond and the other one is free of intermolecular bonds. As these two rings move in phase owing to geometrical constraints, the $\mathrm{C} 22-$ $\mathrm{H} 22$. O 3 hydrogen bond acts as a spring. The small displacements of these rings relative to the rest of the molecule induces small displacements generating deviation from threedimensional periodicity. The less constrained behaviour of the RB2 phenyl ring is also observed in Fig. 6, with a larger evolution along $t$ for RB2 compared with RB1.

$\mathrm{RB} 1$ is less distorted than RB2. This must be related to the existence of a hydrogen bond between $\mathrm{H} 22$ from RB1 and $\mathrm{O} 3$ from a neighbour RB3 molecular part, constraining the position of RB1 constituent atoms. RB2 atoms are then less constrained in position, leading to a more distorted ring,

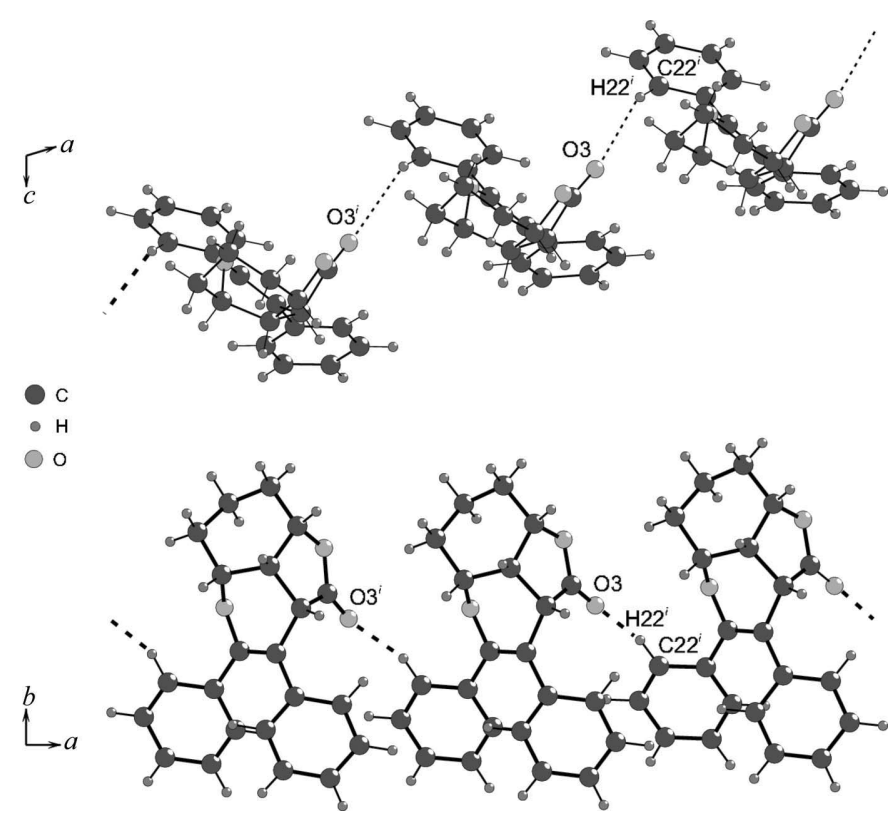

Figure 10

Two different views of the packing structure showing the disposition of the $\mathrm{O} 3 \cdots \mathrm{H} 22$ hydrogen bonds [symmetry code: (i) $-1+x, y, z$ ]. 


\section{research papers}

considering $\mathrm{C}-\mathrm{C}$ distances and angles defining the 'hexagonal' ring. The deviation from the planes between these two different rings is very small and should be considered as insignificant.

Considering the O-atom displacements, we observed that there is a slight displacement along $\mathbf{x}$ and $\mathbf{z}$ (Fig. 5). O atoms, owing to the existence of hydrogen bonds, are more constrained in position, so that the only significant displacement is along the $b$ axis. This corresponds to the global displacement of the molecule in a transverse way compared with the modulation vector.

The refinement of the structure without taking into account the modulation information (commonly referred to as the average structure) yields quite large ADP values for the $\mathrm{C}$ and $\mathrm{O}$ atoms. The introduction of a displacive modulation leads to satisfactory ADP values for all atoms.

This modulation is adequately described with harmonics up to third order. All the molecules are displaced along the $b$ axis. The phenyl rings are also displaced in the two other directions (Fig. 5), with an increase of the displacement from the centre to the exterior of the molecule. The phenyl rings are displaced and rotated in phase with the modulation parameter $t$.

One author (NG) would like to thank Fabrice Camus (Laboratoire de Cristallographie, EPFL, Lausanne, Switzerland) for helpful discussions about IUPAC nomenclature on organic compounds, and Václav Petříček for elucidating symmetry discussions. The Swiss National Science Foundation grant 200020-105325 is gratefully acknowledged.

\section{References}

Baldinozzi, G., Grebille, G., Sciau, Ph., Kiat, J.-M., Moret, J. \& Bérar, J.-F. (1998). J. Phys. Condens. Matter, 10, 6461-6472.

Becker, P. J. \& Coppens, P. (1974). Acta Cryst. A30, 129-147.

Boucher, F., Evain, M. \& Petříček, V. (1996). Acta Cryst. B52, 100109.

Bussien Gaillard, V., Chapuis, G., Dušek, M. \& Petř́ícek, V. (1998). Acta Cryst. A54, 31-43.
Bussien Gaillard, V., Paciorek, W., Schenk, K. \& Chapuis, G. (1996). Acta Cryst. B52, 1036-1047.

Ermer, O. \& Mason, S. A. (1982). Acta Cryst. B38, 2200-2206.

Farrugia, L. J. (1997). J. Appl. Cryst. 30, 565.

Fuhrer, C. A., Messer, R. \& Häner, R. (2004). Tetrahedron Lett. 45, 4297-4300.

Janner, A. \& Janssen, T. (1979). Physica A, 99, 47-76.

Lam, E. J. W., Beurskens, P. T., Smits, J. M. M., van Smaalen, S., de Boer, J. L. \& Fan, H.-F. (1995). Acta Cryst. B51, 779-789.

Messer, R., Pelle, X., Marzinzik, A. L., Lehmann, H., Zimmermann, J. \& Häner, R. (2005). Synlett, pp. 2441-2444.

Messer, R., Schmitz, A., Moesch, L. \& Häner, R. (2004). J. Org. Chem. 69, 8558-8560.

Meyer, M., Paciorek, W. A., Schenk, K. J., Chapuis, G. \& Depmeier, W. (1994). Acta Cryst. B50, 333-343.

Miles, P. A., Kennedy, S. J., McIntyre, G. J., Gu, G. D., Russel, G. J. \& Koshizuka, N. (1998). Physica C, 294, 275-288.

Pan, Y. S., Brown, D. \& Chapuis, G. (2003). Mol. Simul. 29, 509-518.

Pan, Y. S., Chapuis, G. \& Brown, D. (2002). Phys. Rev. B, 65, 184205.

Petříček, V., Dušek, M. \& Palatinus, L. (2003). JANA2000. Institute of Physics, Praha, Czech Republic.

Schaniel, D., Schefer, J., Petř́ček, V., Imlau, M., Pankrath, R., Granzow, T. \& Woike, T. (2002). Appl. Phys. A74 [Suppl.], S963S965.

Schomaker, V. \& Trueblood, K. N. (1968). Acta Cryst. B24, 63-76.

Schönleber, A. \& Chapuis, G. (2004). Acta Cryst. B60, 108-120.

Schönleber, A., Meyer, M. \& Chapuis, G. (2001). J. Appl. Cryst. 34, 777-779. [Available at http://superspace.epfl.ch/nada/www/.]

Shaw, T. M., Shivashankar, S. A., La Placa, S. J., Cuomo, J. J., McGuire, T. R., Roy, R. A. \& Kelleher, K. H. (1988). Phys. Rev. B, 37, 9856-9859.

Sheldrick, G. M. (1990). Acta Cryst. A46, 467-473.

Sheldrick, G. M. (1999). SHELXL97. University of Göttingen, Göttingen, Germany.

Speziali, N. L. \& Pimenta, M. A. (2004). Z. Kristallogr. 219, 737-141.

Steiner, T. (1997). J. Chem. Soc. Chem. Commun. pp. 727-734.

Steiner, T. \& Desiraju, G. R. (1998). J. Chem. Soc. Chem. Commun. pp. 891-892.

Steurer, W. \& Depmeier, W. (1989). Acta Cryst. B45, 555-562.

Stoe (2005). X-Area (V1.26) and X-RED32 (V1.26) Software. Stoe and Cie GmbH, Darmstadt, Germany.

Wolff, P. M. de (1974). Acta Cryst. A30, 777-785.

Wolff, P. M. de (1977). Acta Cryst. A33, 493-497.

Zuñiga, F. J., Madariaga, G., Paciorek, W. A., Pérez-Mato, J. M., Espeleta, J. M. \& Etxebarria, I. (1989). Acta Cryst. B45, 566-576. 